\title{
PRINCÍPIOS ATIVOS INIBIDORES DA GERMINACCÃO IN VITRO DE PÓLEN DE MACIEIRA COMO POTENCIAIS RALEANTES DE FLORAÇÃO
}

\author{
Lucas De Ross Marchioretto ${ }^{1}$, Andrea De Rossi $^{2}$
}

1. Doutorando em Fitotecnia pela Universidade Federal do Rio Grande do Sul (UFRGS), Porto Alegre/RS, Brasil. (lucasdeross@hotmail.com).

2. Pesquisadora em Fitotecnia da Estação Experimental de Fruticultura de Clima Temperado (EFCT) da Embrapa Uva e Vinho, Vacaria/RS, Brasil.

Recebido em: 06/04/2019 - Aprovado em: 10/06/2019 - Publicado em: 30/06/2019 DOI: 10.18677/EnciBio_2019A105

\begin{abstract}
RESUMO
A cultura da macieira possui grande relevância no mercado interno brasileiro, bem como para o mercado externo, sendo um grande exportador da fruta, a nível mundial. Além disso, para se obter frutas com boa aceitação comercial, é necessário o ajuste da carga de frutos nas plantas, através do raleio, que quando feito próximo à antese, apresenta maior efeito sobre o incremento do tamanho de frutos. Entretanto, no Brasil, pouco se sabe sobre a utilização de compostos com capacidade de serem raleantes de flores, na cultura da macieira. Com isso, obejtivou-se avaliar o efeito inibitório de compostos cáusticos, oleosos e hormonais sobre a germinação in vitro de pólen de macieira 'Fuji Suprema'. Para tal, diversos compostos com potencial de inibir a germinação de pólen foram aplicados sobre placas com meio de cultura, onde os grãos de pólen da macieira 'Fuji Suprema' foram colocados para germinar em câmara tipo BOD. Os compostos cáusticos tiossulfato de amônio e calda sulfocálcica, isolada ou associada ao óleo mineral foram efetivos em inibir a germinação in vitro de pólen da macieira 'Fuji Suprema'. Conclui-se que o tiossulfato de amônio e a calda sulfocálcica têm potencial de serem utilizados a campo para promover o raleio de cultivares de macieiras 'Gala', que são polinizadas por cultivares de macieira 'Fuji', no Brasil.
\end{abstract}

PALAVRAS-CHAVE: Cáustico, Óleos emulsionáveis, raleio de flor.

\section{ACTIVE INHIBITOR PRINCIPLES OF IN VITRO MACEDEAN POLLEN GERMINATION AS ROTARY FLOWERING POTENTIALS}

\begin{abstract}
The apple culture has great relevance in the Brazilian domestic market, as well as for the foreign market, being a major exporter of the fruit, worldwide. In addition, in order to obtain fruits with good commercial acceptance, it is necessary to adjust the fruit load in the plants, through the thinning, which when done near the anthesis, has a greater effect on the increment of fruit size. However, in Brazil, little is known about the use of compounds with the ability to be sparse flowers in the apple tree crop. Therefore, the objective of this work was to evaluate the inhibitory effect of caustic,
\end{abstract}


oily and hormonal compounds on the in vitro germination of 'Fuji Suprema' apple pollen. To this end, several compounds with the potential to inhibit pollen germination were applied on plates with culture media, where the pollen grains of the 'Fuji Suprema' apple tree were placed to germinate in a BOD chamber. It was observed that the caustic compounds ammonium thiosulfate and lime sulphur solution isolated or associated with mineral oil were effective in inhibiting the in vitro germination of 'Fuji Suprema' apple pollen. It is concluded that ammonium thiosulfate and lime sulphur have the potential to be used in the field to promote the thinning of 'Gala' apple cultivars, which are pollinated by 'Fuji' apple cultivars in Brazil.

KEYWORDS: Caustic, Emulsionable oils, Flower thinning.

\section{INTRODUÇÃO}

A cultura da macieira possui grande importância econômica e social no Brasil, sendo que no ano de 2017, o país produziu cerca de 1.300 mil toneladas da fruta (IBGE, 2019). No Brasil, a maçã é a terceira fruta mais comercializada, atrás apenas da laranja e do mamão (HF BRASIL, 2019), indicando aumento no consumo de maçã no mercado interno nos últimos anos. Além do grande mercado interno brasileiro, a exportação da fruta tem aumentado nas últimas safras, especialmente para novos mercados consumidores em países como Bangladesh, Irlanda e Portugal; além disso, há grande expectativa de exportação para a Índia, e Colômbia, o que demostra a demanda dos mercados para a maçã brasileira (ANUÁRIO, 2018). Com o avanço da tecnologia no sistema produtivo da maçã, hoje o Brasil é um importante "player" no comércio global da fruta, sendo o décimo maior produtor no mundo (USDA, 2019).

Para que o fruto da macieira tenha boa aceitação comercial, em especial, um tamanho grande, o manejo da carga de frutos deve ser feito, buscando-se o equilíbrio entre a produção de assimilados e a produção de frutos (GREENE; COSTA, 2013). A macieira é sensível à competição por assimilados na fase inicial do desenvolvimento do fruto; isso ocorre porque após a fecundação e início da multiplicação celular do fruto, há grande demanda por assimilados, bem como essa demanda ocorre pelos diversos frutos de uma mesma inflorescência e as gemas vegetativas nos ramos que se encontram em pleno desenvolvimento no início da primavera; sendo assim, há pouca área fotossintética na planta e a fonte de energia principal vem das reservas do ano anterior (LAKSO; GOFFINET, 2013).

Os frutos de macieira possuem três momentos principais de desenvolvimento durante o período de crescimento do fruto, sendo, até aproximadamente 10 dias após a plena floração (DAPF) o crescimento provindo somente de multiplicação celular, cuja fase garante o potencial do tamanho final do fruto; num segundo momento, entre 10 DAPF e cinco semanas, o crescimento ocorre tanto por divisão celular quanto por expansão celular, e, na fase final que vai até a maturação, o crescimento ocorre somente por expansão celular (LAKSO; GOFFINET, 2013). Dessa forma, segundo os mesmos autores, quanto mais próximo da antese o raleio for realizado, maior será a taxa de multiplicação celular, que consequentemente levará à maior tamanho final.

Uma importante alternativa é a utilização de raleantes cáusticos durante a antese, buscando diminuir a quantidade de flores fecundadas, e dessa forma, diminuir a competição (LAKSO; GOFFINET, 2013), além disso, alguns raleantes possuem potencial de serem utilizados na produção orgânica de macieira, como alternativa ao raleio manual (PECK et al., 2016; LEE et al., 2018). 
Dentre os raleantes utilizados durante a antese, há os compostos cáusticos que agem causando danos ao estigma ou impedindo o contato do grão de pólen, e também inibindo a germinação dos grãos de pólen na superfície do estigma; há também compostos oleosos que agem interferindo na respiração do grão de pólen, impedindo ou paralisando o crescimento do tubo polínico (MARCHIORETTO et al., 2019); e, reguladores de crescimento, que possuem pouco efeito direto sobre o processo de fecundação, mas agem nos processos fisiológicos que afetam o suprimento de assimilados aos frutos em desenvolvimento (KORALIČ et al., 2011).

Experimentos têm demostrado que nas condições climáticas do Sul do Brasil, os raleantes de floração são efetivos quando aplicados no momento correto, para diversas espécies frutíferas de clima temperado (MARCHIORETTO et al., 2018; CARMINATTI et al., 2018; MARCHIORETTO et al., 2019). Entretanto, ainda não há informações disponíveis a respeito da eficiência de compostos cáusticos, oleosos ou hormonais na inibição da germinação de pólen de macieira 'Fuji'. Dessa forma, objetivou-se avaliar o efeito inibitório na germinação de pólen de macieira 'Fuji Suprema' de diversos princípios ativos, como forma de avaliar a potencialidade dos mesmos serem utilizados como raleantes de floração, em macieiras 'Gala'.

\section{MATERIAIS E MÉTODOS}

Durante a antese da macieira 'Fuji Suprema', que iniciou no dia 10 de outubro de 2017, em um pomar experimental localizado na Estação Experimental de Fruticultura de Clima Temperado da EMBRAPA Uva e Vinho, no município de Vacaria-RS, foram coletadas flores em estádio fenológico de balão rosado, que foram armazenadas em sacos de papel e levados ao laboratório para a extração do pólen. A extração do pólen se deu pela remoção do perianto com o auxílio de uma tesoura adaptada com um orifício na ponta, para então, com um pente com dentes espaçados a aproximadamente $1 \mathrm{~mm}$, onde os filetes foram direcionados contra os dentes, forçando o descolamento das anteras, que foram acondicionadas em bandejas de papel, com bordas de $2 \mathrm{~cm}$ de altura, e colocadas sob uma câmara de secagem com uma lâmpada de 40 watts à temperatura constante de 20 a $25^{\circ} \mathrm{C}$, por 24 horas. Após a deiscência das anteras, o pólen foi armazenado em congelador convencional a $-18{ }^{\circ} \mathrm{C}$ em tubos Eppendorf ${ }^{\circledR} \mathrm{com} 1 \mathrm{~mL}$ de capacidade sendo as amostras mantidas em dessecador contendo sílica gel.

Os tratamentos avaliados nesse experimento foram: ácido naftaleno acético $\left(0,0105 \mathrm{~g} \cdot \mathrm{L}^{-1}\right)$, Benziladenina $\left(3 \mathrm{~mL} \mathrm{~L}^{-1}\right)$, Benziladenina + Ácido giberélico $\left(2,5 \mathrm{~mL} \mathrm{~L}^{-}\right.$ $\left.{ }^{1}\right)$, Calda sulfocálcica $\left(30 \mathrm{~mL} \mathrm{~L}^{-1}\right)$, Calda sulfocálcica + Óleo mineral $\left(20+20 \mathrm{~mL} \mathrm{~L}^{-1}\right)$, Fertilizante foliar $\left(0,5 \mathrm{~mL} \mathrm{~L}^{-1}\right)$, Óleo mineral $\left(20 \mathrm{~mL} \mathrm{~L}^{-1}\right)$, Óleo vegetal $\left(25 \mathrm{~mL} \mathrm{~L}^{-1}\right)$, Tiossulfato de amônio (25 $\left.\mathrm{g} \mathrm{L}^{-1}\right)$, Uréia $\left(16 \mathrm{~g} \mathrm{~L}^{-1}\right)$, Uréia $\left(32 \mathrm{~g} \mathrm{~L}^{-1}\right)$, e uma testemunha não tratada. A avaliação do efeito dos tratamentos sobre a germinação do pólen, foi realizada seguindo metodologia de Franzon e Raseira (2006). Para tanto, foi preparado meio de cultura, composto de $1000 \mathrm{~mL}$ de água destilada, $100 \mathrm{~g}$ de sacarose e $10 \mathrm{~g}$ de ágar, misturando-se bem até a completa dissolução e colocando a mistura em forno microondas até o início da fervura. Então, enquanto a mistura ainda estava quente, e líquida, a mesma foi colocada em lâminas de microscópio adaptadas com dois anéis de PVC com $14 \mathrm{~mm}$ de diâmetro e $3 \mathrm{~mm}$ de altura, num total de três lâminas para cada tratamento, incluindo uma testemunha não tratada, num total de seis discos (repetições) para cada tratamento. Após a solidificação do meio de cultura, procedeu-se à aplicação dos tratamentos através de um borrifador plástico com capacidade para $500 \mathrm{~mL}$, sendo que cada lâmina 
recebeu sete borrifadas, para garantir que se formasse uma película com os princípios ativos. A solução contendo os princípios ativos foi preparada em Beckers com $500 \mathrm{~mL}$ de capacidade, sendo adicionados em todos os tratamentos o espalhante adesivo Break Thru ${ }^{\circledR}$ a $0,15 \% \mathrm{v} / \mathrm{v}$. Após a secagem da calda, ao toque, o pólen foi distribuído sobre o meio de cultura com o uso de um pincel impregnado com o pólen de 'Fuji Suprema'.

Posteriormente à aplicação dos tratamentos, as lâminas foram alocadas dentro de placas de Petry ${ }^{\circledR}$ contendo papel filtro umedecido com água destilada, disposto em dupla camada, simulando uma câmara úmida, para serem colocados em câmaras tipo BOD a $25^{\circ} \mathrm{C}$ por um período de três horas. Passado o período de incubação, os discos de PVC nas lâminas foram avaliados com microscópio ótico (10 x 100), sendo contados aproximadamente 100 grãos de pólen, segregando-se entre não germinados e germinados. Neste caso, para o grão de pólen ser considerado germinado, o tubo polínico deveria ter ao menos o comprimento do grão de pólen.

Os dados foram analisados quanto à normalidade pelo teste de Shapiro-Wilk $(p<0,05)$ e transformados por raiz quadrada para ter os pressupostos da análise de variância. Os dados transformados foram submetidos à análise de variância $(p<0,05)$ e as médias foram comparadas pelo teste de Tukey $(p<0,05)$. Todos os testes estatísticos foram feitos com o software Sisvar v.5.6 (FERREIRA, 2014)

\section{RESULTADOS E DISCUSSÃO}

Houve efeito significativo de tratamento $(p<0,01)$ para o percentual de grãos de pólen germinados (Tabela 1). Os tratamentos cáusticos calda sulfocálcica isolada ou associada ao óleo mineral apresentaram o efeito mais agressivo em relação à inibição da germinação de pólen de macieira 'Fuji Suprema'. Enquanto que o pólen tratado com tiossulfato de amônio, também cáustico, apresentou baixa germinação dos grãos de pólen. Em contraste, ambos tratamentos contendo uréia, que possui efeito cáustico sobre tecidos vegetais, não interferiram negativamente na germinação do pólen.

TABELA 1. Efeito de diferentes compostos sobre o percentual de germinação in vitro de grãos de pólen de macieira 'Fuji Suprema'.

\begin{tabular}{lcc}
\hline Tratamentos $^{1}$ & $\begin{array}{c}\text { Doses de produto } \\
\text { comercial }\end{array}$ & $\begin{array}{c}\text { Percentual de grãos de } \\
\text { pólen de macieira 'Fuji } \\
\text { Suprema' germinados }\end{array}$ \\
\hline Testemunha não tratada & - & $50 \mathrm{ab}$ \\
Ácido naftaleno acético & $0,0105 \mathrm{~g} / \mathrm{L}$ & $44 \mathrm{ab}$ \\
Benziladenina & $3,0 \mathrm{~mL} / \mathrm{L}$ & $47 \mathrm{ab}$ \\
Benziladenina + Ácido giberélico $4+7$ & 2 & $53 \mathrm{a}$ \\
Calda sulfocálcica & $2,5 \mathrm{~mL} / \mathrm{L}$ & $0 \mathrm{~d}$ \\
Calda sulfocálcica + Óleo mineral & $30 \mathrm{~mL} / \mathrm{L}$ & $1 \mathrm{~d}$ \\
Fertilizante foliar & $20+20 \mathrm{~mL} / \mathrm{L}$ & $33 \mathrm{~b}$ \\
Óleo mineral & $0,5 \mathrm{~mL} / \mathrm{L}$ & $46 \mathrm{ab}$ \\
Óleo vegetal & $20 \mathrm{~mL} / \mathrm{L}$ & $36 \mathrm{~b}$ \\
Tiossulfato de amônio & $25 \mathrm{~mL} / \mathrm{L}$ & $10 \mathrm{c}$ \\
Uréia & $25 \mathrm{~g} / \mathrm{L}$ & $33 \mathrm{~b}$ \\
\hline
\end{tabular}




\begin{tabular}{lcc}
\hline Uréia & $32 \mathrm{~g} / \mathrm{L}$ & $41 \mathrm{ab}$ \\
\hline$P$ value & - & $<0,01$ \\
CV $(\%)$ & - & 13,59
\end{tabular}

${ }^{1}$ Foi adicionado o adjuvante espalhante adesivo Break Thru ${ }^{\circledR}$, na dose de $0,15 \%$ v/v à calda de todos os tratamentos. ${ }^{2}$ Dose do produto comercial Promalina ${ }^{\circledR}$.

Resultados similares foram relatados por Stopar (2008), em que calda sulfocálcica na dose de $30 \mathrm{~mL} \mathrm{~L}^{-1}$ teve o efeito mais severo como raleante de flores da macieira 'Golden Delicious', porém com 'Summerred' o raleio de frutos não foi efetivo com calda sulfocálcica, mas foi com óleo vegetal, sugerindo diferentes níveis de interação entre diferentes cultivares de macieira e compostos cáusticos ou oleosos. Por exemplo, para ameixeira 'Letícia', tanto óleo vegetal (3\%) quanto cloreto de cálcio (2\%) foram efetivos no raleio de flores (CARMINATTI et al., 2018). Para macieira 'Fuji Suprema', no Sul do Brasil, que é polinizada por 'Gala', o pólen desta cultivar (Gala) apresentou-se mais suscetível aos efeitos inibitórios da germinação in vitro, sendo inibido por óleo vegetal, tiossulfato de amônio, benziladenina isolada ou associada ao ácido giberélico ${ }_{4+7}$, além de calda sulfocálcica isolada ou associada ao óleo mineral (MARCHIORETTO et al., 2019).

Nesse experimento, o tiossulfato de amônio teve efeito inibitório menor, em relação à calda sulfocálcica, na germinação de pólen de 'Fuji Suprema'; mas para efeitos práticos utilizando-o como raleante de flores à campo, o composto se mostrou efetivo, na mesma dose testada nesse experimento, para diminuir a frutificação efetiva e melhorar a qualidade de frutos de 'Maxi Gala' (MARCHIORETTO et al., 2018).

Óleos emulsionáveis são efetivos, à campo, quando aplicados durante a floração de macieira e pessegueiro, quando aplicados antes do início da floração e $20 \%$ de flores abertas (JU et al., 2001). Porém, como demonstrado nesse experimento, o óleo mineral não age diretamente sobre a inibição da germinação de pólen. Até pouco tempo, acreditava-se que óleos emulsionáveis agiam por criarem uma barreira física sobre o estigma das flores, e dessa forma, impedindo a penetração do tubo polínico, ou criando uma camada lipídica que impediria a fixação do pólen sobre a superfície estigmática (EMBREE; FOSTER, 1999). Entretanto, hoje sabe-se que o mecanismo de ação dos óleos emulsionáveis ocorre por não interferir substancialmente na germinação do pólen sobre o estigma, mas por paralisar o desenvolvimento do tubo polínico no estilo (MARCHIORETTO et al., 2019).

Os compostos cáusticos, como o tiossulfato de amônio e a calda sulfocálcica apresentam $\mathrm{pH}$ alcalino, o que interfere negativamente no desenvolvimento do tubo polínico (MICHARD et al., 2017). O ápice do tubo polínico apresenta pH acidificado devido à grande quantidade de bombas de prótons, que transportam elétrons para o exterior, visando a criação de um gradiente eletroquímico negativo no interior do ápice para que ocorra a entrada de íons de $\mathrm{Ca}^{2+}$, que servem para estabilizar os filamentos de pectina (componentes constituintes do tubo polínico) e permitir que o tubo cresça até encontrar o óvulo (HEPLER et al., 2013). O mesmo fenômeno pode ser observado por Montag et al. (2005), em que conídios do fungo Venturia inaequalis tiveram a germinação dos apressórios inibidas por calda sulfocálcica. Os autores concluíram que o mecanismo de ação envolvido foi o $\mathrm{pH}$ extremamente elevado da calda sulfocálcica, que ficou acima de 12, e com isso, promoveu o colapso das membranas e tecidos, mas em pH levemente alcalino, não houve inibição da germinação de conídios. No caso da uréia, a mesma tem efeito necrótico quando aplicada em altas doses no solo, devido à grande 
quantidade, mas para nível de raleio de flores, ela não se mostre eficiente porque ela não eleva o pH do meio a um nível impactante para a inibição da germinação de pólen, pois segundo Mello (1980), a uréia eleva o pH até próximo da neutralidade.

Durante a elongação do tubo polínico, até a fecundação, há enorme dispêndio de energia respiratória, das mitocôndrias, principalmente para o funcionamento de bombas de prótons, que são um mecanismo de transporte ativo (GAO et al., 2014). Ainda segundo os autores, quando há perda de função das mitocôndrias, há acidificação do citosol e isso bloqueia a entrada de íons para o interior do tubo polínico, como o $\mathrm{Ca}^{+2}$, pelo interior da célula ter o mesmo gradiente eletroquímico que o exterior, levando à paralisia do crescimento. Nesse experimento, é possível que o óleo vegetal tenha provocado algum efeito deletério na germinação do pólen, por criar uma barreira física e bloqueando as trocas gasosas entre o grão de pólen e o ar externo, e dessa forma asfixiando-o. Segundo Marchioretto et al. (2019), o óleo mineral, ou o vegetal não impedem a germinação dos grãos de pólen sobre o estigma da flor de macieira, mas impede o desenvolvimento do tubo polínico no interior do pistilo.

Nesse experimento, apesar de não ter havido diferença estatística, o pólen tratado com benziladenina + ácido giberélico ${ }_{4+7}$, apresentou, numericamente, maior percentual de germinação, em relação à testemunha. Maita e Sotomayor (2015) relataram que a germinação de pólen de amendoeira (Prunus dulcis) em meio de cultura contendo reguladores de crescimento giberelina ou citocinina, promoveram maior germinação, e, no caso da giberelina, os grãos de pólen tiveram maior comprimento de tubo polínico. Porém, segundo os autores, quando aplicado a campo, durante a floração da amendoeira, os tratamentos aumentaram a frutificação efetiva, devido à melhores taxas de fecundação devido a tubos polínicos mais desenvolvidos.

\section{CONCLUSÃO}

Os compostos cáusticos calda sulfocálcica, isolada ou associada ao óleo mineral, e, o tiossulfato de amônio são efetivos em inibir a germinação de pólen de macieira 'Fuji Suprema' in vitro.

Dessa forma, tais compostos têm potencial de serem testados ou utilizados a campo para o raleio da macieira 'Gala', que tradicionalmente são polinizadas por macieiras 'Fuji' no Brasil.

\section{REFERÊNCIAS}

ANUÁRIO BRASILEIRO DA MAÇÃ. Santa Cruz do Sul: Editora Gazeta Santa Cruz, 2018. 56p.

CARMINATTI, G.F.; MARCHIORETTO, L.R.; FRANCESCATTO, P.; ROSSI, A. RUFATO, L. Efficacy of chemical agents in reducing fruit set of 'Leticia' japanese plums. Agrarian Academy, v.5, n.10, p.74-81, 2018. Disponível em: <http://www.conhecer.org.br/Agrarian\%20Academy/2018B/efficacy.pdf>. doi: 10.18677/Agrarian_Academy_2018B8

EMBREE, C.G.; FOSTER, A. Effects of Coatings and Pollenicides on Pollen Tube Growth Through the Stigma and Style of 'Mclntosh' Apple Blossoms. Journal of Tree Fruit Production, v.2, n.2, 1999. Disponível em:< 
https://www.tandfonline.com/doi/abs/10.1300/J072v02n02_03>.

doi: 10.1300/J072v02n02_03

FERREIRA, D.F. Sisvar: A Guide for its Bootstrap procedures in multiple comparisons. Ciênc. agrotec. [online]. 2014, v.38, n.2, p. 109-112, 2014. Disponível em: http://dx.doi.org/10.1590/S1413-70542014000200001.

FRANZON, R.C.; RASEIRA, M.C.B. Germinação in vitro e armazenamento do pólen de Eugenia involucrata DC (Myrtaceae). Revista Brasileira de Fruticultura, v.28, n.1, p.18-20, 2006. Disponível em: <http://www.scielo.br/scielo.php?pid=S010029452006000100008\&script=sci_arttext\&tIng=es >. doi: 10.1590/S010029452006000100008

GAO, Y.; ZHOU, H.; CHEN, J,; JIANG, X,; TAO, S. et al. Mitochondrial dysfunction mediated by cytoplasmic acidification results in pollen tube growth cessation in Pyrus pyrifolia. Physiologia Plantrum, v.153, n.4, p.603-615, 2014. Disponível em: <https://onlinelibrary.wiley.com/doi/full/10.1111/ppl.12260>. doi: 10.1111/ppl.12260

GREENE, D.; COSTA, G. Fruit thinning in pome- and stone-fruit: state of the art. Acta Horticulturae, v.998, p.93-102, 2013. Disponível em: <https://www.actahort.org/books/998/998 10.htm>. doi: 10.17660/ActaHortic.2013.998.10

HEPLER, P.K.; ROUNDS, C.M.; WINSHIP, L.J. Control of cell wall extensibility during pollen tube growth. Molecular Plant, v.6, n.4, p.998-1017, 2013. Disponível em: <https://doi.org/10.1093/mp/sst103>. doi: $10.1093 / \mathrm{mp} / \mathrm{sst} 103$

HF BRASIL. HORTIFRUTI/CEPEA, 2019. Quais foram as frutas mais vendidas em 2017?. Disponível em: https://www.hfbrasil.org.br/br/hortifruti-cepea-quais-foram-asfrutas-mais-vendidas-em-2017.aspx. Acesso em: 5 jan. 2019.

IBGE. Produção Agrícola Municipal. 2019. Disponível em:< https://sidra.ibge.gov.br/tabela/5457\#resultado>. Acesso em: 15 mar/2019.

JU, Z.; DUAN, Y,; JU, Z.; GUO, A. Corn oil emulsion for early bloom thinning of trees of 'Delicious' apple, 'Feng Huang' peach, and 'Bing' cherry. The Journal of Horticultural Science and Biotechnology, v.76, n.3, p. 327-331, 2001. Disponível em: $\quad<$ http://dx.doi.org/10.1080/14620316.2001.11511371>. doi: 10.1080/14620316.2001.11511371

KOLARIČ,J.; PLEŠKO, I.M.; TOJNKO, S.; STOPAR, M. Apple Fruitlet Ethylene Evolution and mdaco1, mdacs5a, and mdacs5b Expression after Application of Naphthaleneacetic Acid, 6-Benzyladenine, Ethephon, or Shading. HortScience, v.46, n.10, p.1381-1386, $2011 . \quad$ Disponível em: <https://journals.ashs.org/hortsci/view/journals/hortsci/46/10/article-p1381.xmL>. doi: https://doi.org/10.21273/HORTSCI.46.10.1381

LAKSO, A.N.; GOFFINET, M.C. Apple fruit growth. New York Quarterly, v.21, n.1, p.11-14, 2013.

Disponível em: 
<http://www.hort.cornell.edu/expo/proceedings/2014/Tree\%20Fruit/Apple\%20Fruit\%2 0Growth\%20Lakso.pdf>.

LEE, S.H.; LEE, S.M.; SO, S.; CHOI, Y.S.; JANG, Y.H. et al. Effect on flower thinning by using nano-processing technology chemicals in plum (Prunus salicina Linnaeus). Net Journal of Agricultural Science, v.6, n.3, p.42-48, 2018. Disponível em: < http://www.netjournals.org/z_NJAS_18_023.htmL>. doi: 10.30918/NJAS.63.18.023

MAITA, S.; SOTOMAYOR, C. The effect of three plant bioregulators on pollen germination, pollen tube growth and fruit set in almond [Prunus dulcis (Mill.) D.A.Webb] cvs. Non Pareil and Carmel. Electronic Journal of Biotechnology, v.18, p.381-386, $2015 . \quad$ Disponível em: <https://www.sciencedirect.com/science/article/pii/S0717345815000974>. doi: 10.1016/j.ejbt.2015.07.004

MARCHIORETTO, L.R.; ROSSI, A.; AMARAL, L.O.; RIBEIRO, A.M.A.S. Efficacy and mode of action of blossom thinners on 'Fuji More' apple trees. Scientia Horticulturae, v.246, p.634-642. Disponível em: < https://www.sciencedirect.com/science/article/pii/S0304423818308203>. doi: https://doi.org/10.1016/j.scienta.2018.11.039.

MARCHIORETTO, L.R.; ROSSI, A.; MICHELON, M.F.; ORLANDI, J.C.; AMARAL, L.O. Ammonium thiosulfate as blossom thinner in 'Maxi Gala' apple trees. Pesquisa Agropecuária Brasileira, v.53, n.10, p.1131-1139, 2018. Disponível em: $<$ http://www.scielo.br/scielo.php?script=sci_arttext\&pid=S0100-

204X2018001001132\&lng=en\&tlng=en>. doi: 10.1590/S0100-204X2018001000006

MELLO, F. A. F.; DE POSSÍDIO, E. L.; PEREIRA, J. R.; DE ARAÚJO, J. P.; ABRAMOF, L. et al. Efeito da adição de uréia e sulfato de amônio sobre o pH e nitrificação em um solo ácido. Anais da Escola Superior de Agricultura Luiz de Queiroz, v.37, n.1, p.1-10, 1980. Disponível em: < http://dx.doi.org/10.1590/S007112761980000100001.>. doi: 10.1590/S0071-12761980000100001

MICHARD, E.; SIMON, A.A.; TAVÁRES, B.; WUDICK, M.M.; FEIJÓ, J.A. Signaling with lons: The Keystone for Apical Cell Growth and Morphogenesis in Pollen Tubes.

Plant Physiology, v.173, p.91-111, 2017. Disponível em:

<http://www.plantphysiol.org/content/173/1/91>. doi: 10.1104/pp.16.01561

MONTAG, J.; SCHREIBER, L.; SCHÖNHERR, J. An in vitro Study on the Postinfection Activities of Hydrated Lime and Lime Sulphur against Apple Scab (Venturia inaequalis). Journal of Phytopathology, v.153, p.485-491, 2005. Disponível em: < https://doi.org/10.1111/j.1439-0434.2005.01007.x>. doi: 10.1111/j.1439-0434.2005.01007.x

PECK, G.M.; COMBS, L.D.; DELONG, C.; YODER, K.S. Precision apple flower thinning using organically approved chemicals. Acta Horticulturae, v.1137, p. 47-52, 2016. Disponível em: < https://doi.org/10.17660/ActaHortic.2016.1137.7>. doi: 10.17660/ActaHortic.2016.1137.7 
STOPAR, M. Vegetable Oil Emulsions, $\mathrm{NaCl}, \mathrm{CH} 3 \mathrm{COOH}$ and $\mathrm{CaSx}$ as Organically Acceptable Apple Blossom Thinning Compounds. European Journal of Horticultural Science, v.72, n.2, p.55-61, 2008. Disponível em: <https://www.pubhort.org/ejhs/2008/596535.htm>.

USDA. Foreign Agricultural Service, 2019. Fresh Deciduous Fruit: World Markets and Trade (Apples, Grapes, \& Pears). Disponível em: < https://apps.fas.usda.gov/psdonline/circulars/fruit.pdf>. Acesso em: 16 dez. 2018. 